\title{
Diagnóstico molecular de Neospora caninum en fetos abortados espontáneamente en bovinos de Uruguay
}

\section{Molecular diagnosis of Neospora caninum in aborted bovine fetus from Uruguay}

\begin{tabular}{ll}
\hline${\text { Carolina Briano }{ }^{*} \text { 0000-0002-5295-9550 }}_{\text {Javier Regidor-Cerrillo² 0000-0001-5831-6970 }}$ & Agustín Romero ${ }^{1}$ 0000-0001-5110-1846 \\
Cristina Easton1 0000-0002-4841-5139 & Pablo Peraza ${ }^{1}$ 0000-0001-6822-0307 \\
Florencia Pieruccioni ${ }^{1}$ 0000-0003-0007-8329 & América Mederos ${ }^{4}$ 0000-0003-2404-7121 \\
${ }^{1}$ División de Laboratorios Veterinarios “Miguel C. Rubino” (DI.LA.VE), M.G.A.P., Uruguay. \\
*Autor para correspondencia: cbriano@mgap.gub.uy \\
${ }^{2}$ Grupo SALUVET. Departamento de Sanidad Animal. Facultad de Veterinaria, Universidad Complutense de Madrid, España. \\
Instituto Nacional de Investigación Agropecuaria (I.N.I.A.). \\
${ }^{3}$ Unidad de Biotecnología, Estación Experimental I.N.I.A. Las Brujas, Ruta 48 Km10, Canelones, Uruguay. \\
${ }^{4}$ Instituto Nacional de Investigación Agropecuaria (I.N.I.A.). Programa Producción de Carne y Lana. Estación Experimental I.N.I.A. \\
Tacuarembó. Ruta 5 km 386, Tacuarembó, Uruguay.
\end{tabular}

Veterinaria (Montevideo) Volumen 57 № 216 (2021 Jul - Dic) e20215721603

\section{Resumen}

En Uruguay el diagnóstico de rutina de Neospora caninum se realiza fundamentalmente por estudios histopatológicos de los fetos abortados, complementando esta información con resultados de serología y/o Inmunohistoquímica (IHQ). El objetivo de este estudio fue estandarizar un protocolo de amplificación de secuencias mediante PCR (polymerase chain reaction) para la detección de Neospora caninum en órganos de fetos abortados espontáneamente en bovinos para su incorporación a la rutina diagnóstica. Con este propósito se realizó un estudio retrospectivo utilizando muestras congeladas de archivo, de un periodo comprendido entre los años 2013 y 2016, con diagnóstico positivo o negativo a Neospora caninum. Los resultados mostraron que de 31 muestras positivas a Neospora caninum por las técnicas de rutina, 26 fueron positivas por PCR (84\%), demostrando una alta sensibilidad de diagnóstico de esta técnica. Todas las muestras con diagnóstico negativo mediante histopatología $(n=20)$ fueron confirmadas como negativo mediante PCR. La comparación de los resultados de PCR con los de histopatología, mediante el test de Cohen's Kappa, señalaron un acuerdo muy alto $(81 \%, \mathrm{p}<0.001)$ entre ambos diagnósticos. Dichos resultados sumados a la simplicidad y rapidez de la técnica podrían sugerir a la PCR como alternativo de la IHQ como técnica confirmatoria en el diagnóstico de rutina. También permitiría realizar análisis retrospectivos de muestras archivadas, paso fundamental para futuros estudios genéticos de la población de Neospora caninum presente en Uruguay. Palabras claves: Diagnóstico, Neospora caninum, PCR.

\begin{abstract}
The diagnosis of Neospora caninum in Uruguay is carried out by histopathological studies of aborted fetuses, complementing this information with serology test and/or immunohistochemistry (IHC) results. The aim of this study was to standardize a protocol of polymerase chain reaction (PCR) to detect of $\mathrm{N}$. caninum in organs of spontaneously aborted bovine fetus. A retrospective study was conducted using frozen samples from a period between 2013 and 2016, with positive or negative diagnosis of N. caninum. Results showed that 26 of 31 samples positives for N. caninum by routine techniques were positive by PCR, demonstrating a high sensitivity of the PCR. All negative samples by Histopathology ( $n=20)$ were confirmed as negative by PCR. Cohen's Kappa test indicated a very high agreement $(81 \%, \mathrm{p}<0.001)$ between PCR and Histopathology with serology test and/or immunohistochemistry (IHC) results. The high sensitivity, specificity and simplicity of PCR test suggest this technique as an alternative to IHC as a confirmatory technique in routine diagnosis. Keywords: Diagnosis, Neospora caninum, PCR.
\end{abstract}




\section{Introducción}

La neosporosis es considerada una de las principales causas de aborto infeccioso en bovinos en Uruguay y el mundo (Al-Qassab et al., 2009; Dubey, 2003; Dubey y Schares, 2011; Easton, 2006; Moore, 2005). La amplia difusión de la neosporosis en Uruguay se ha observado tanto en ganado para leche como para carne, afectando gravemente ambos sectores (Macchi et al., 2020; Piaggio, 2011). Esta enfermedad es causada por Neospora caninum ( $N$. caninum) un protozoario tisular e intracelular obligado, perteneciente junto a Toxoplasma, Isospora y Sarcosystis al phylum Apicomplexa (Thilsted y Dubey, 1989). En Uruguay, el diagnóstico de esta enfermedad en los fetos se realiza aplicando pruebas de laboratorio en forma seriada. Primero se realiza la necropsia y la histopatología de los fetos, incluyendo el análisis histológico exhaustivo del sistema nervioso central con la coloración de hematoxilina-eosina (HP). De encontrarse la lesión histológica característica (focos de necrosis con gliosis periférica), se realiza la identificación de las formas parasitarias por inmunohistoquímica (IHQ) y/o serología positiva de la madre y/o el feto (Easton, 2006). Esta combinación seriada de técnicas diagnósticas, -en la que sí y solo sí, se realiza el diagnóstico final si todas las pruebas son positivas-, asegura una muy alta especificidad diagnóstica y se considera como la prueba de referencia para el diagnóstico de la enfermedad en los fetos (Baszler et al., 2001; Reichel et al., 2018). Sin embargo, la identificación de las formas parasitarias por IHQ, si bien es altamente específica, es una técnica muy laboriosa y analíticamente poco sensible (Dubey, 2003; Easton, 2006). Otras pruebas de laboratorio que se han utilizado para el diagnóstico son el aislamiento por inoculación y citocultivo, pero estas técnicas son en extremo complejas y costosas (Bañales et al., 1999; Bañales et al., 2006). En tal sentido, en nuestro país se han logrado aislar 4 cepas de N. caninum de terneros persistentemente infectados, pero no así de fetos abortados (Cabrera et al., 2019).

Una alternativa a la IHQ es la incorporación de técnicas moleculares como PCR, la cual es altamente específica, sensible y rápida (Müller et al., 1996). La PCR puede ser aplicada a una amplia gama de muestras, como ser tejidos de fetos de la especie en estudio u hospedadores intermedios de la enfermedad, líquido amniótico, líquido cefalorraquídeo, heces, sangre, leche y semen (Dubey et al., 2006). Para el desarrollo de PCR de diagnóstico de $N$. caninum se ha utilizado una serie de genes blancos como ser el ADN ribosomal 18S, el ADN ribosomal 28S, la región interna del espaciador transcrito 1 del gen ARNr (ITS 1), el gen pNc5 y el gen 14-3-3 (Cabral et al., 2009; Goodswen et al., 2013; Mûller et al., 1996; Payne y Ellis, 1996; Yamage et al., 1996). Las PCRs que amplifican elementos repetitivos suelen tener una mayor sensibilidad analítica en comparación con las PCRs que amplifican fragmentos de genes de copia única. En tal sentido, los genes que codifican ARNr (18S rDNA, 28S rDNA, ITS1) y el gen pNc5 son objetivos importantes para el diagnóstico cualitativo y cuantitativo de $N$. caninum por PCR. La utilización de ITS1 como gen blanco ha demostrado gran utilidad en la identificación de especie de $N$. caninum (Dubey et al., 2006; Goodswen et al., 2013). La PCR se ha realizado en uno o en dos pasos (nested PCR), siendo este último de mayor sensibilidad, pero con la desventaja de tener mayor riesgo de contaminación. Una alternativa para evitar este problema es realizar el nested PCR en un solo tubo, lo que combina así la alta sensibilidad con bajos riesgos de contaminación. La sensibilidad analítica más alta reportada en la literatura fue de 0.1-0.01 taquizoítos/g (Dubey et al., 2006). La alta sensibilidad y especificidad de dicha técnica, ha hecho de este gen blanco (ITS1) uno de los más empleados. La limitante de esta técnica (PCR), -sino se utiliza en forma seriada con casos positivos por histopatología, - es poder establecer una relación causa-efecto entre el aborto y N. Caninum, ya que las infecciones congénitas asintomáticas son comunes y por lo tanto, solo la presencia del parásito o el ADN del parásito no significa que N. caninum haya causado el aborto (Dubey et al. 2007, Dubey y Schares, 2011). Algo similar sucede con la serología materna positiva, la cual solo indica exposición y no causa del aborto y para la cual no hay prueba de referencia (Campero et al.., 2015).

El objetivo de este estudio fue seleccionar, estandarizar y evaluar para incorporar a la rutina diagnóstica, como alternativa al IHQ y/o serología materna, un protocolo de amplificación de secuencias mediante PCR (polymerase chain reaction) para la detección de Neospora caninum en órganos de fetos abortados espontáneamente en bovinos.

\section{Materiales y métodos}

El trabajo se llevó a cabo en el Laboratorio de biotecnología de la Dirección de Laboratorios Veterinarios (DI.LA.VE) Regional Este. Para este propósito se utilizaron muestras congeladas de archivo de un período comprendido entre los años 2013 y 2016, con diagnóstico positivo $(\mathrm{n}=31)$ a $N$. caninum de acuerdo al protocolo de rutina que implica Histopatología más serología (fetal y/o materna) y/o Inmunohistoquímica (IHQ). La prueba de Inmunohistoquímica (IHQ) se realizó de acuerdo al protocolo descripto por Haines et al., 1992 y modificado por Easton (2006). Adicionalmente, se seleccionaron 20 muestras con resultados de histopatología negativa a $N$. caninum para ser usadas como control.

\section{Puesta a punto de la PCR y condiciones}

La extracción de ADN de las muestras seleccionadas fue realizada usando un kit comercial (DNeasy blood y tissue QIAGEN) de acuerdo al protocolo del fabricante.

ElADN obtenido fue teñido con Orange DNA(ThermoScientific) y colocado en el gel por 30 minutos a 100 volts. El gel utilizado fue un gel de agarosa al 1.5\%, diluido en buffer TAE con SYBR ${ }^{\circledR}$ Safe DNA gel stain (Invitrogen) como intercalante a una concentración de 1:10.000. Posteriormente fue visualizado en un transiluminador de luz ultravioleta para evaluar su cantidad y calidad. 
Tabla 1: Secuencia y características de los cebadores seleccionados

\begin{tabular}{|c|c|c|c|c|c|}
\hline Nombre & Tipo & Secuencia (5'a $\left.3^{\prime}\right)$ & $\% \mathrm{GC}$ & $\begin{array}{l}\text { Temperatura de } \\
\text { anniling }\left({ }^{\circ} \mathrm{C}\right)\end{array}$ & Longitud \\
\hline TGNN1 & Exterior & CCTTTGAATCCCAAGCAAAACATGAG & 42 & 61.8 & 26 \\
\hline TGNN2 & Exterior & GCGAGCCAAGACATCCATTGCTGA & 54 & 61.8 & 24 \\
\hline NP1 & Interno & TACTACTCCCTGTGAGTTG & 74 & 58.1 & 19 \\
\hline NP2 & Interno & ТСТСТТСССТСАAАCGCT & 50 & 58.1 & 18 \\
\hline
\end{tabular}

De los protocolos disponibles en la literatura, se aplicó el PCR modificada de Buxton et al. (1998) y descripto por RegidorCerrillo et al. (2014), que amplifica la región ITS1 de Neospora caninum reportado por Payne y Ellis (1996).

Los cebadores utilizados fueron los descriptos en la Tabla 1.

La reacción de amplificación de $\mathrm{ADN}$ fue optimizada para un volumen final de $25 \mu \mathrm{L}$, que contiene: $5 \mu \mathrm{L}$ de $\mathrm{ADN}$ genómico, $0.125 \mu \mathrm{L}$ de cebadores internos de $10 \mu \mathrm{M}, 1 \mu \mathrm{L}$ de cebadores externos de $10 \mu \mathrm{M}, 5.25 \mu \mathrm{L}$ de agua ultrapura y $12.5 \mu \mathrm{L}$ Mango mix (Bioline).

Como control negativo agua ultra pura y como control positivo ADN extraído de aislados de $N$. caninum proporcionados por el Grupo SALUVET de la Facultad de Veterinaria de la Universidad Complutense de Madrid.

El protocolo térmico estandarizado fue el siguiente: desnaturalización inicial a $94^{\circ} \mathrm{C}$ durante tres minutos, seguido de 15 ciclos de $94^{\circ} \mathrm{C}$ durante 30 segundos, $65^{\circ} \mathrm{C}$ por 45 segundos y $72^{\circ} \mathrm{C}$ por 1 minuto. Luego por 35 ciclos de $94^{\circ} \mathrm{C}$ durante 30 segundos, $54^{\circ} \mathrm{C}$ por 1 minuto y $72^{\circ} \mathrm{C}$ por 1 minuto, terminando con una extensión a $72^{\circ} \mathrm{C}$ por 5 minutos. El producto de PCR se separó por electroforesis (30 minutos a 100 volts) en un gel de agarosa al $1.5 \%$ (diluido en buffer TAE con SYBR ${ }^{\circledR}$ Safe DNA gel stain como intercalante a una concentración de $10.000 \mathrm{X}$ ) y visualizó bajo luz ultravioleta y foto documento. El amplicón tiene un tamaño esperado de $275 \mathrm{pb}$.

Para confirmar los resultados obtenidos, se enviaron 26 amplicones a secuenciar en MACROGEN (Korea). La información obtenida de las 26 secuencias fue analizada con las secuencias consenso y de referencia para N. caninum, utilizando las herramientas BLAST (Basic Local AlignmentSearchTool) y BioEdit (BioEdit-SequenceAlignment Editor), así como con las de Toxoplasma gondii, Sarcocystis sp. y Hammondia spp.

\section{Análisis estadístico}

Para el estudio de la concordancia entre resultados de la Histopatología-serología/ Histopatología-IHQ y los resultados obtenidos por PCR, se utilizó el coeficiente de Cohen's Kappa (k) y la interpretación de los valores de $\mathrm{K}$ adoptados fueron: $\leq 0=$ desacuerdo; $0.01-0.2=$ escaso; 0.21-0.40=escaso; 0.41-0.60=moderado; 0.61-0.80= adecuado; 0.81-1.00=excelente (Landis y Koch, 1977). Para los cálculos de kappa se utilizó el programa informático MiniTab.

\section{Resultados}

De las 31 muestras registradas como positivas a $N$. caninum por Histopatología-serología/ Histopatología-IHQ (Diagnóstico de rutina), en 26 (84\%) se observó una banda compatible con la esperada para ITS-1 de $275 \mathrm{pb}$. Las 20 muestras con resultado negativo (por histopatología) a $N$. caninum todas fueron negativas a la prueba de PCR.

El análisis de las secuencias del amplicón permitió confirmar dicho resultado, así como comprobar que las secuencias amplificadas no son comunes con Toxoplasma gondii, Sarcocystis sp. y Hammondia spp.

En la Tabla 2 se muestran los resultados de la comparación entre Histopatología-serología/ Histopatología-IHQ ("pruebas de referencia”) y PCR para $N$. caninum. El resultado del estadístico Kappa indica una muy buena concordancia entre el diagnóstico Histopatología-serología/ Histopatología-IHQ y PCR. La sensibilidad del PCR frente a la prueba de referencia fue de $84 \%$ y su especificidad de $100 \%$.

Tabla 2: Resultados del acuerdo entre los Histopatología-serología/ Histopatología-IHQ y PCR para N. caninum.

\begin{tabular}{lcccccc}
\hline & \multicolumn{2}{c}{$\begin{array}{c}\text { HISTOPATOLOGIA } \\
\text { (más serología y/o IHQ) }\end{array}$} & Valor de P & Kappa & Sens. & Espec. \\
PCR & Positivo & Negativo & & $(\mathrm{K})$ & $(\%)$ & $(\%)$ \\
\hline Positivo & 27 & 0 & $<0,0001$ & 0,81 & 84 & 100 \\
Negativo & 5 & 20 & & & \\
& 32 & 20 & & & \\
\hline
\end{tabular}

Sens $=$ Sensibilidad; Espec $=$ Especificidad 


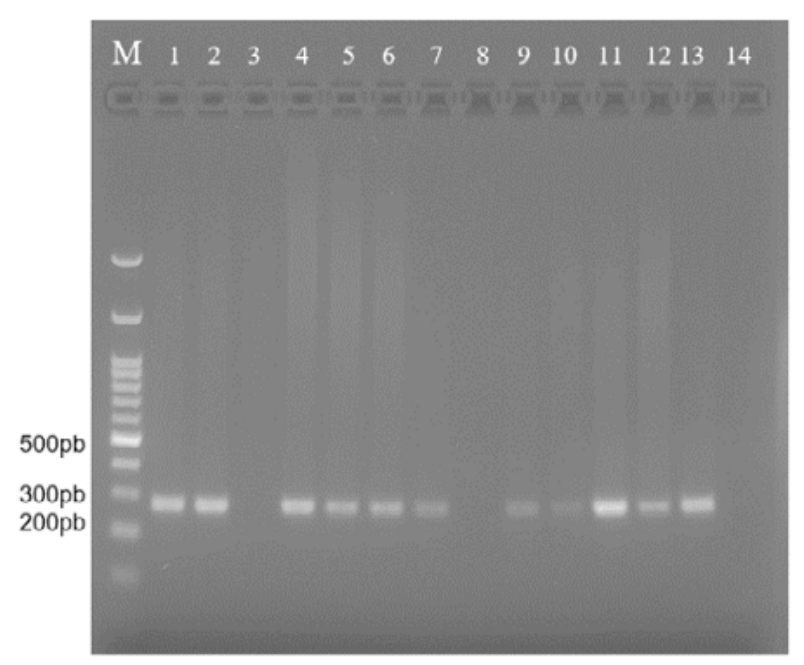

Figura 1: Visualización de productos de PCR provenientes de muestras positivas para Neospora caninum en gel de agarosa al 1,5\%, M: marcador de peso molecular $100 \mathrm{pb}$ (Bioline), 1 al 12 corresponde a muestras de archivo diagnosticadas como positivas mediante técnicas de rutina, 13: Control positivo y 14: Control negativo.

La Figura 1 muestra el resultado correspondiente al producto de Nested PCR obtenido de 12 muestras de fetos bovinos abortados con diagnóstico positivo por Histopatologíaserología/ Histopatología-IHQ a $N$. caninum, en el cual ,10 de las mismas presentan un fragmento de $275 \mathrm{pb}$ correspondientes a N. caninum.

\section{Discusión}

Las muestras conservadas a $-20^{\circ} \mathrm{C}$ proporcionaron un ADN de suficiente calidad para realizar los trabajos propuestos. Los resultados encontrados muestran que la técnica de nested PCR en un solo tubo puede ser implementado con éxito para el diagnóstico complementario de $N$. caninum en muestras de tejidos de materiales conservados en forma congelada.

La realización del Nested PCR en un solo tubo resolvió el problema de contaminación, no detectándose en todo el estudio, fallas por esta causa. Esta alternativa fue utilizada por Ellis et al., (1999), para evitar este problema, obteniendo muy buenos resultados, al igual que en este estudio.

La técnica de PCR reportó una muy buena performance, lo que se evidenció en la alta sensibilidad (84\%) y especificidad (100\%) así como por el valor de Kappa (0.81), que según Landis y Koch, (1977), revela excelente concordancia entre el diagnóstico actual de rutina y PCR. Dicho resultado no indica una evaluación de la calidad de las pruebas.

En comparación con la Histopatología-serología/ Histopatología -IHQ, la técnica de PCR falló en detectar 5 muestras registradas positivas. De acuerdo con la literatura, trabajos de Ellis et al. (1999) en un estudio similar, reportó una sensibilidad analítica de $0.1-0.01$ taquizoítos. Si bien en este estudio no se midió la sensibilidad analítica de la PCR, las muestras negativas podrían presentar una concentración muy baja del patógeno, por debajo del límite de detección. Una de las posibles causas podría ser fallas en el muestreo (Dubey, 2003). El procedimiento de muestreo es afectado por la calidad de la muestra, la autolisis es muy frecuente en las muestras de campo que llegan de rutina al laboratorio por sospecha de $N$. caninum. Dicha autolisis dificulta seriamente la identificación de las zonas del sistema nervioso central (SNC) lo que sumado a la distribución focal y no homogénea de los taquizoítos en el SNC compromete el éxito del muestreo.

De acuerdo con Dubey (2003), el examen histológico del feto es necesario para un diagnóstico definitivo de neosporosis bovina (Dubey, 2003) cuya lesión más característica es una encefalitis focal por necrosis e inflamación no supurativa (Barr et al., 1991). La IHQ al mostrar el parásito en la lesión descripta por histopatología es la mejor demostración de que el aborto se debe a $N$. caninum, pero como ya fue mencionado, dicha técnica tiene la desventaja de ser poco sensible (Dubey, 2003).

Esto mismo quedó en evidencia con nuestros resultados, ya que la sensibilidad de la IHQ para nuestros datos fue de $62 \%$ y sensiblemente menor a la obtenida por PCR.

La sensibilidad y especificidad de la PCR sumado a su simplicidad y rapidez podría sugerir a la PCR como alternativo de la IHQ como técnica confirmatoria en el diagnóstico de rutina.

\section{Conclusión}

El protocolo estandarizado en este estudio presentó alta especificidad y sensibilidad para la detección de $N$. caninum en muestras de campo de fetos abortados. Esto demuestra que cuando dicha técnica se utiliza en forma seriada junto a cambios histopatológicos significativos en los tejidos de los fetos abortados, es una valiosa herramienta de confirmación para el diagnóstico de $N$. caninum en el ganado vacuno.

También permite realizar análisis retrospectivos de muestras archivadas, paso fundamental para futuros estudios genéticos de la población de $N$. caninum presente en Uruguay.

\section{Agradecimientos}

A la Agencia Nacional de Investigación e Innovación (AN.I.I.) por la financiación de la beca de Doctorado de Carolina Briano. El trabajo fue financiado en parte con fondos del proyecto FSSA_X_2014_1_103894 de A.N.I.I.-I.N.I.A.

A la Lic. Laura Rodríguez Yáñez por su valioso aporte en la corrección del texto.

\section{Conflicto de Interés}

Los autores no tienen conflictos de interés para declarar. 


\section{Referencias bibliográficas:}

Al-Qassab, S., Reichel, M.P., Ivens, A., y Ellis, J.T. (2009). Genetic diversity amongst isolates of Neospora caninum, and the development of a multiplex assay for the detection of distinct strains. Molecular and Cellular Probes, 23 (3-4), 132-139.

Bañales, P., Easton, C., Haritani, M., Kashiwazaki, Y., Paullier, C., y Pizzorno, M. (1999). Aborto bovino por Neospora caninum en el Uruguay: Primer diagnóstico. Veterinaria, 34, 28-32.

Bañales, P., Fernandez, L., Repiso, M. V., Gil, A., Dargatz, D. A., y Osawa, T. (2006). A nationwide survey on seroprevalence of Neospora caninum infection in beef cattle in Uruguay. Veterinary Parasitology, 139(1-3), $15-20$.

Barr, B.C., Anderson, M.L., Dubey, J.P., y Conrad, P.A. (1991). Neospora-like Protozoal Infections Associated with Bovine Abortions. Veterinary Pathology, 28(2), 110116.

Baszler, T. V., Adams, S., Vander-Schalie, J., Mathison, B. A., y Kostovic, M. (2001). Validation of a commercially available monoclonal antibody-based competitiveinhibition enzyme-linked immunosorbent assay for detection of serum antibodies to Neospora caninum in cattle. Journal of Clinical Microbiology, 39(11), 38513857.

Buxton, D., Maley, S.W., Wright, S., Thomson, K.M., Rae, A.G., y Innes, E.A. (1998). The pathogenesis of experimental neosporosis in pregnant sheep. Journal of Comparative Pathology, 118, 267-279.

Cabral, A.D., Camargo, C.N., Cacciatori, N.T., Okuda, L.H., Maristela, E., y Del Fava, C. (2009). Diagnosis of Neospora caninum in bovine fetuses by histology, immunohistochemistry, and nested-PCR. Revista Brasileira de Parasitologia Veterinária, 18(4), 14-19.

Cabrera, A., Fresia, P., Berná1, L., Silveira, C., Macías-Rioseco, M., Arevalo, A., ...Robello1, C. (2019) Isolation and molecular characterization of four novel Neospora caninum strains. Parasitology Research, 118, 35353542

Campero, L. M., Minke, L., Moré, G., Rambeaud, M., Bacigalupe, D., Moore, D.P., ...Venturini, M.C. (2015). Evaluation and comparison of serological methods for the detection of bovine neosporosis in
Argentina. Revista Argentina de microbiologia, 47(4), 295-301. doi: 10.1016/j.ram.2015.07.002

Dubey, J.P. (2003). Review of Neospora caninum and neosporosis in animals. Korean Journal of Parasitology, 41(1), $1 \square 16$.

Dubey, J.P., Buxton, D., y Wouda, W. (2006). Pathogenesis of bovine neosporosis. Journal of Comparative Pathology, 134, 267-289.

Dubey, J.P., y Schares, G. (2011). Neosporosis in animals--the last five years. Veterinary Parasitology, 180(1-2), 90-108.

Dubey, J.P., Schares, G., y Ortega-Mora, L. (2007). Epidemiology and Control of Neosporosis and Nesopora caninum. Clinical Microbiology Reviews, 20(2), 323-367.

Easton, C. (2006). Estudio Patológico de las Principales Causas Infecciosas en el Aborto Bovino en Uruguay (Tesis de Maestría). Facultad de Veterinaria, UDELAR, Montevideo. Recuperado http://www. sidalc.net/cgibin/wxis.exe/?IsisScript=FVL. xis\&method $=\% 20$

Ellis, J.T., McMillan, D., Ryce, C., Payne, S., y Atkinson, R., Harper, P.A.W. (1999). Development of a single tube nested polymerase chain reaction assay for the detection of Neospora caninum DNA. International Journal for Parasitology, 29, 1589-1596.

Goodswen, S.J., Kennedy, P.J., y Ellis, J.T. (2013). A review of the infection, genetics, and evolution of Neospora caninum: From the past to the present. Infection, Genetics and Evolution, 13, 133-150.

Haines, D. M., Clark, E. G., y Dubovi, E. J. (1992). Monoclonal antibody-based immunohistochemical detection of bovine viral diarrhea virus in formalin-fixed, paraffinembedded tissues. Veterinary Pathology, 29(1), 2732.

Landis, J., y Koch, G. (1977). An Application of Hierarchical Kappa-type Statistics in the Assessment of Majority Agreement among Multiple Observers. Biometrics, 33(2), 363-374.

Macchi, M.V., Suanes, A., Salaberry, X., Fernandez, F., Piaggio, J., y Gil, A.D. (2020). Epidemiological study of neosporosis in Uruguayan dairy herds. Preventive Veterinary Medicine, 179, 105022. doi: 10.1016/j. prevetmed.2020.105022

Moore D. P. (2005). Neosporosis in South America. Veterinary Parasitology, 127(2), 87-97. 
Müller, N., Zimmermann, V., Hentrich, B., y Gottstein, B. (1996). Diagnosis of Neospora caninum and Toxoplasma gondii infection by PCR and DNA hybridization immunoassay. Journal of Clinical Microbiology, 34(11), 2850-2852.

Payne, S., y Ellis, J. (1996). Detection of Neospora caninum DNA by the polymerase chain reaction. International Journal for Parasitology, 26(4), 347-351.

Piaggio, J. (2011). Neosporosis bovina: Estudios Epidemiológicos en Uruguay. INIA Serie Actividades de Difusión, 655, 17-42.

Regidor-Cerrillo, J., Arranz-Solís, D., Benavides, J., GómezBautista, M., Castro-Hermida, J.A., Mezo, M., ... González-Warleta, M. (2014). Neospora caninum infection during early pregnancy in cattle: how the isolate influences infection dynamics, clinical outcome and peripheral and local immune responses. Veterinay Research, 45, 10.

Reichel, M.P., Wahl, L.C., y Hill, F.I. (2018). Review of diagnostic procedures and approaches to infectious causes of reproductive failures of cattle in Australia and New Zealand. Frontiers in Veterinary science, 5 , 222.
Thilsted, J.P., y Dubey, J.P. (1989). Neosporosis-like abortions in a herd of dairy cattle. Journal of Veterinary Diagnostic, 1(3), 205-209.

Yamage, M., Flechtner, O., y Gottstein, B. (1996). Neospora caninum: specific oligonucleotide primers for the detection of brain "cyst" DNA of experimentally infected nude mice by the polymerase chain reaction (PCR). Journal of Parasitology, 82(2), 272-279.

\section{Nota de contribución:}

1. Concepción y diseño del estudio, 2. Adquisición de datos, 3. Análisis de datos, 4. Discusión de los resultados, 5. Redacción del manuscrito, 6. Aprobación de la versión final del manuscrito.

Carolina Briano 1-2-3-4-5-6

Javier Regidor-Cerrillo 1-4-6

Cristina Easton 1-2-4-6

Florencia Pieruccioni 2-4-6

Agustín Romero 2-4-6

Pablo Peraza 2-3-6

América Mederos 1-2-4-6

Fernando Dutra 1-3-4-5-6

\section{Nota del Editor:}

El editor Cecilia Cajarville aprobó este artículo. 